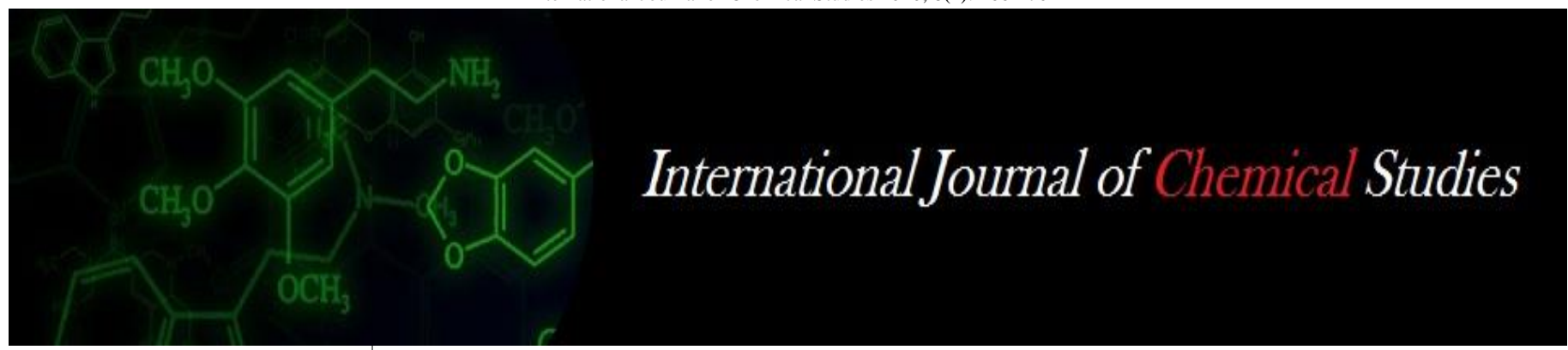

P-ISSN: 2349-8528

E-ISSN: 2321-4902

www.chemijournal.com

IJCS 2020; 8(4): 266-270

(C) 2020 IJCS

Received: 28-05-2020

Accepted: 30-06-2020

Priyanka Priyadarsini

Department of Agril.

Engineering, School of

Agriculture, GIET University,

Gunupur, Odisha, India

Abhinab Mishra

Department of Agril.

Engineering, School of

Agriculture, GIET University,

Gunupur, Odisha, India

Corresponding Author: Priyanka Priyadarsini

Department of Agril.

Engineering, School of

Agriculture, GIET University,

Gunupur, Odisha, India

\section{A storage study of value added oyster mushroom products}

\author{
Priyanka Priyadarsini and Abhinab Mishra
}

DOI: $\underline{\text { https://doi.org/10.22271/chemi.2020.v8.i4d.9703 }}$

\begin{abstract}
Oyster mushroom (Pleurotus ostreatus) is an edible mushroom of the kingdom Mycetae and belongs to the family Agaricaceae. Significant amount of oyster mushroom is grown in Odisha particularly in winter season, when there is shortage of paddy straw mushroom in the market. Though it has got all the nutritional factors compared to all other type of mushrooms, unlike paddy straw and button mushroom, oyster mushroom has a bland taste which is not very much liked by the consumers. Generally farmers do not get remunerative price for cultivating this type of mushroom because almost entire domestic trade is in the fresh form while most of the export is in the preserved form (canned or steeped). Current era is characterized by greater awareness about quality and, above all, with the demand for the readymade or ready-to-make food products. As mushrooms contain high moisture and are delicate in texture, these cannot be stored for more than 24 hours at the ambient conditions of the tropics. This leads to weight loss, veil opening, browning, liquefaction and microbial spoilage of the product making it unsaleable. Effective processing techniques will not only prevent the post-harvest losses but also result in greater remuneration to the growers as well as to the processors. The objective of the study was therefore, to prepare oyster mushroom value added products using both fresh and powdered oyster mushrooms and study the shelf life of mushroom ketchup in two different packaging materials like glass bottle and PET bottle and mushroom soup powder in LDPE pouch, HDPE pouch, PP pouch and aluminium foil. For storage, it was concluded that glass bottle storage is preferred for oyster mushroom ketchup and laminated aluminium pouch was considered the best for oyster mushroom soup powder.
\end{abstract}

Keywords: Oyster mushroom, shelf life, storage, mushroom ketchup, soup powder

\section{Introduction}

The focus of Indian mushroom industry is predominantly on trade of the fresh produce rather than the real value-addition. Almost entire domestic trade is in the fresh form while most of the export is in the preserved form (canned or steeped). Mushrooms have very short shelflife, these cannot be stored or transported for more than 24 hours at the ambient conditions prevailing in most parts of year and the country. Browning, veil-opening, weight-loss and microbial spoilage are the most common postharvest changes in the mushrooms which often result into enormous economic losses (Ahlawat et al,.2000a) ${ }^{[2]}$. Proper, sound and appropriate postharvest practices of storage and processing are needed to sustain the budding mushroom farming and industry in the country. This leads to weight loss, veil opening, browning, liquefaction and microbial spoilage of the product making it unsalable. Effective processing techniques will not only prevent the post harvest losses but also result in greater remuneration to the growers as well as to the processors (Ahlawat et al,.2000b) ${ }^{[3]}$.

Value can be added to the mushrooms at various levels, right from grading to the readymade snacks or the main-course items. Real value-added product in the Indian market is the mushroom soup powder. Technologies for production of some other products like mushroom based biscuits, nuggets, preserves, noodles, papad, candies and readymade mushroom curry in retort pouches have been developed but are yet to be popularized (Adsule, P.G et.al.) and (Arumuganathan, and Hemakar, 2003) ${ }^{[6]}$.

Oyster mushroom (Pleurotus ostreatus) is an edible mushroom of the kingdom Mycetae and belongs to the family Agaricaceae. It has a distinctive oyster like flavour when cooked. The oyster mushroom grows from $5-10 \mathrm{~cm}$ tall and has irregular lobed white, yellow or grey cap (Anonymous 2017 b). Significant amount of oyster mushroom is grown in Odisha particularly in winter season, when there is shortage of paddy straw mushroom in the market. 
It is comparatively easier to produce oyster mushroom. Though it has got all the nutritional factors compared to all other type of mushrooms, unlike paddy straw and button mushroom, oyster mushroom has a bland taste and it is not very much liked by the consumers. Generally farmers do not get remunerative price for cultivating this type of mushroom. So it is felt to prepare different types of value added products using both fresh and powdered oyster mushrooms, so as to get a remunerative price realization to the farmers and growers of oyster mushroom. The objective of the study was therefore, to prepare oyster mushroom value added products (mushroom soup powder and mushroom ketch up) using both fresh and powdered oyster mushrooms, also study the storage characteristics of the value added oyster mushroom products.

\section{Materials and Methods}

Freshly harvested oyster mushrooms (Pleurotus sp.) were procured from market immediately after harvest and were washed thoroughly under running tap to remove adhering extraneous matter. The brown and damaged portions of mushroom were removed. Washed and cleaned mushrooms were taken for the experimental studies (Czapski, 2002) ${ }^{[8]}$. The experiment was conducted at CAET, OUAT, Bhubaneswar.

\section{Preparation of oyster mushroom soup powder}

Dried whole oyster mushrooms were finely ground in a pulveriser and passed through $0.5 \mathrm{~mm}$ sieve. Mushroom soup powder was prepared by mixing this powder with milk power, corn flour and other ingredients as given in the table. This has to be mixed with equal quantity of water for the preparation of good quality mushroom soup with characteristic aroma and taste. By observing the ingredients proportions of different types of soup powders available in local super market, the ingredients for the proposed oyster mushroom soup powder was formulated. Mushroom powder was used in different proportions of $10,15,20,25 \%$ respectively, whereas the proportions of other ingredients were kept constant.

Table 1: Percentage of ingredients in oyster mushroom soup powder

\begin{tabular}{|c|c|c|}
\hline Sr. No. & Ingredients & Parts in percentage \\
\hline $\mathbf{1}$ & Mushroom powder & $10,15,20 \& 25$ \\
\hline 2 & Corn flour & 5 \\
\hline 3 & Milk powder & 50 \\
\hline 4 & Refined oil & 4 \\
\hline 5 & Salt & 10 \\
\hline 6 & Cumin powder & 2 \\
\hline 7 & Black pepper & 2 \\
\hline 8 & Sugar & 10 \\
\hline 9 & Ajinomoto & 2 \\
\hline
\end{tabular}

\section{Preparation of oyster Mushroom Ketch-Up}

Freshly harvested oyster mushrooms are washed, sliced and cooked in $50 \%$ of water for 20 minutes. Mushroom paste is prepared using a mixer grinder. Arrarote $(0.2 \%)$, acetic acid $(1.5 \%)$ and other ingredients are mixed in the paste and cooked to bring its TSS to $35^{\circ} \mathrm{Brix}$. Then the ketch-up is filled in the sterilized bottles or jars (Das and Pattanayak 2003) ${ }^{[9]}$.

Table 2: Percentage of ingredients in oyster mushroom ketchup

\begin{tabular}{|c|c|c|}
\hline Sr. No. & Ingredients & Parts in percentage \\
\hline $\mathbf{1}$ & Salt & 10 \\
\hline 2 & Sugar & 25 \\
\hline 3 & Acetic acid & 1.5 \\
\hline 4 & Sodium Benzoate & 0.065 \\
\hline 5 & Onion & 10 \\
\hline 6 & Garlic & 0.5 \\
\hline 7 & Ginger & 3 \\
\hline 8 & Cumin & 1 \\
\hline 9 & Black Pepper & 0.1 \\
\hline 10 & Red chilly powder & 1 \\
\hline 11 & Ajinomoto & 0.2 \\
\hline 12 & Arrowroot & 0.2 \\
\hline
\end{tabular}

\section{Packaging of Mushroom Products}

After standardization of value added products different types of available packaging materials were tried for storage study in room temperature condition. Glass bottle and PET (Polyethylene Terephthalate) Bottle are chosen as packaging materials of oyster mushroom ketchup.

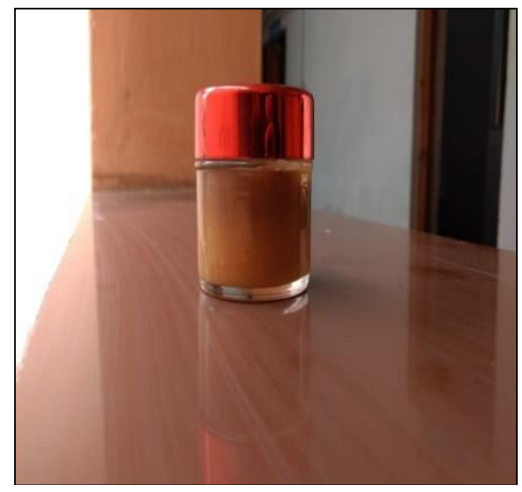

Fig 1: Glass bottle storage

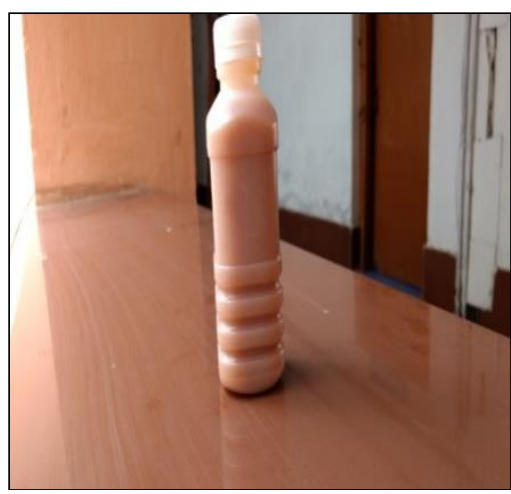

Fig 2: PET bottle storage

Table 3: Packaging materials for oyster mushroom soup powder

\begin{tabular}{|c|c|}
\hline Sample no. & Packaging material \\
\hline 1 & LDPE (Low-density polyethylene) \\
\hline 2 & HDPE (High-density polyethylene) \\
\hline 3 & PP (Polypropylene) \\
\hline 4 & Laminated Aluminium Foil \\
\hline
\end{tabular}




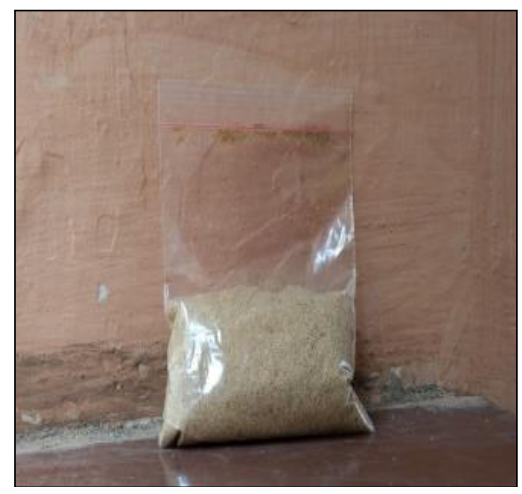

Fig 3: LDPE pouch

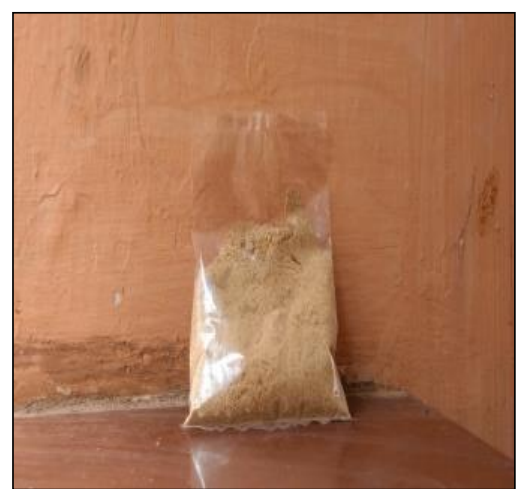

Fig 4: PP pouch

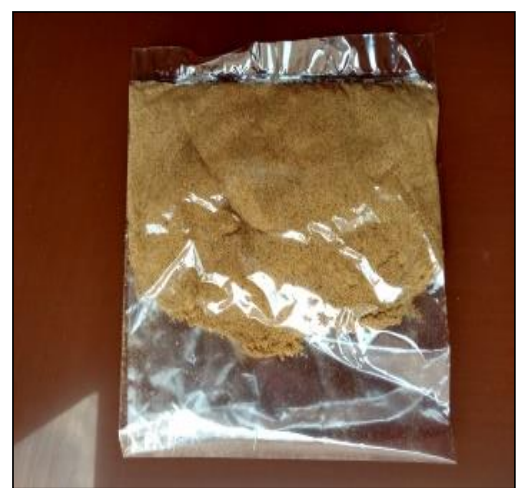

Fig 5: HDPE pouch

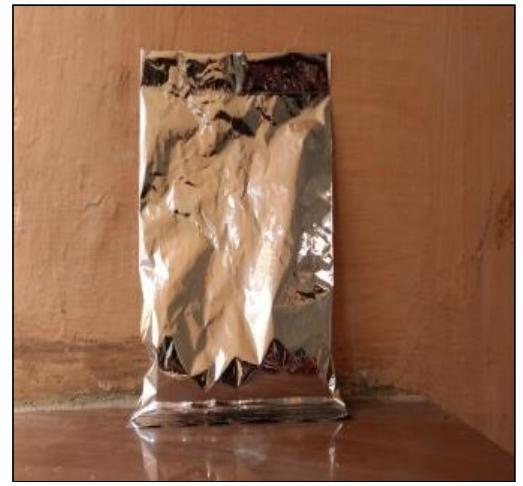

Fig 6: Laminated Aluminum Foil

\section{Storage Study of Mushroom Value Added Products}

Both the products in different types of packaging materials were kept in room temperature condition for the storage study. Different parameters like moisture content, acidity, ascorbic acid, colour (L, a, b value) and reducing sugar were studied.

\section{Moisture Content Determination}

The moisture content of raw ingredients was determined by oven drying method (ASTA, 1985; Ranganna, 1986). The raw samples kept in the oven were observed to come to equilibrium condition after $24 \mathrm{hr}$ at $70^{\circ} \mathrm{c}$. Subsequently, for determination of initial moisture content, the three replications were kept in oven for $24 \mathrm{hr}$ at $70{ }^{\circ} \mathrm{C}$. The initial moisture content of sample was calculating using this formula.

$$
\begin{aligned}
& \text { M.C. } \%(\text { w.b. })=100 \times \frac{\left(w_{2}-w_{3}\right)}{\left(w_{2}-w_{1}\right)} \\
& \text { M.C. } \% \text { (d.b. })=100 \times \frac{\left(w_{2}-w_{3}\right)}{\left(w_{3}-w_{1}\right)}
\end{aligned}
$$

Where,

$\mathrm{W}_{1}=$ Weight of the moisture dish along with its cover

$\mathrm{W}_{2}=$ Weight of the moisture dish along with sample

$\mathrm{W}_{3}=$ Weight of the moisture dish along with the dried sample

\section{Acidity Determination}

Acidity was determined by dissolving a known weight of sample in distilled water and titration against $0.1 \mathrm{~N} \mathrm{NaOH}$ using phenolphthalein as indicator.

\section{Ascorbic Acid Determination}

Dye preparation: $0.5 \mathrm{gms}(2,6)$ Dicholoro-phenol indo phenol dye was added to $150 \mathrm{ml}$ of hot distilled water containing $0.042 \mathrm{gms}$ of sodium bicarbonate. Then it was cooled and volume was made up to $200 \mathrm{ml}$ with distilled water in a volumetric flask. L-ascorbic acid preparation (stock solution): $0.1 \mathrm{gms}$ of L-ascorbic acid was taken in a $100 \mathrm{ml}$ volumetric flask \& made up to volume with $3 \%$ metaphosphoric acid.

Standard solution: $10 \mathrm{ml}$ of stock ascorbic acid solution was taken in a $100 \mathrm{ml}$ volumetric flask \& made up to volume with $3 \%$ meta-phosphoric acid.

Standardization of dye: $5 \mathrm{ml}$ of standard ascorbic acid solution with $5 \mathrm{ml}$ of $3 \%$ meta-phosphoric acid was titrated against indophenol dye to a light pink end point to get the dye factor.For determining the ascorbic acid content of the RTS, $5-10 \mathrm{ml}$ of the prepared sample was taken in a conical flask and titrated against the above dye to a light pink.

\section{Colour (L, a, b Value) Determination}

Colour (L, a, b and Yellowness Index) of ground sample was measured by using Hunter Lab colorimeter (model no. 45/0L, made in U.S.A). The $\mathrm{L}^{*}$ value presents the lightness of the product colour from 100 for perfect white to 0 for black. The redness/greenness and yellowness/blueness are denoted by the ' $a$ '' and ' $b$ ', values, respectively.

\section{Reducing Sugar Determination}

Reducing sugar was determinted by DNS method. Dinitrosalicylic Acid Reagent (DNS Reagent). $1 \mathrm{~g}$ dinitrosalicylic acid, $200 \mathrm{mg}$ crystalline phenol and $50 \mathrm{mg}$ sodium sulphite in $100 \mathrm{~mL} 1 \% \mathrm{NaOH}$ were dissolved by stirring and stored at $4{ }^{\circ} \mathrm{C}$. 0.5 to $3 \mathrm{~mL}$ of the extract pipette out in test tubes and equalize the volume to $3 \mathrm{~mL}$ with water in all the tubes. $3 \mathrm{~mL}$ of DNS reagent were added to each tube. The contents were heated in a boiling water bath for 5 min. When the contents of the tubes are still warm, $1 \mathrm{~mL}$ of $40 \%$ Rochelle salt solution added. The content was cooled 
and the intensity of dark red colour at $510 \mathrm{~nm}$ was determined.

\section{Results and Discussions}

The results obtained from the standardization and storage studies of oyster mushroom value added products.
Observations regarding sensory score, moisture content, acidity, ascorbic acid, colour ( $\mathrm{L}, \mathrm{a}, \mathrm{b}$ value) and reducing sugar have been presented and discussed.

Quality Tests for value added oyster mushroom products

Table 4: Change in quality parameters of oyster mushroom ketchup with time

\begin{tabular}{|c|c|c|c|c|c|}
\hline \multicolumn{6}{|c|}{ Glass Bottle } \\
\hline Time period(days)) & Moisture content $(\%)$ & \begin{tabular}{|l|} 
Acidity (\%) \\
\end{tabular} & Ascorbic acid (\%) & \begin{tabular}{|l|} 
Colour $(\mathbf{l}, \mathbf{a}, \mathbf{b})$ \\
\end{tabular} & Reducing sugar $(\%)$ \\
\hline 0 & 68.01 & 0.81 & 9.04 & $\begin{array}{c}\mathrm{l}=15.87 \\
\mathrm{a}=5.7 \\
\mathrm{~b}=6.02\end{array}$ & 7.63 \\
\hline 15 & 65.78 & 0.89 & 8.92 & $\begin{array}{c}\mathrm{l}=17.96 \\
\mathrm{a}=5.6 \\
\mathrm{~b}=6.2\end{array}$ & 7.98 \\
\hline 30 & 63.81 & 1.08 & 8.67 & $\begin{array}{c}\mathrm{l}=20.01 \\
a=5.2 \\
b=6.43\end{array}$ & 9.03 \\
\hline 45 & 60.13 & 1.95 & 8.6 & $\begin{array}{c}\mathrm{l}=22.86 \\
a=5.4 \\
b=6.76\end{array}$ & 9.41 \\
\hline \multicolumn{6}{|c|}{ PET bottle } \\
\hline 0 & 64.37 & 1.02 & 14.02 & $\begin{array}{c}l=20.04 \\
a=6.86 \\
b=5.02\end{array}$ & 11.03 \\
\hline 15 & 60.37 & 1.07 & 13.96 & $\begin{array}{l}\mathrm{l}=20.4 \\
\mathrm{a}=6.2 \\
\mathrm{~b}=6.5\end{array}$ & 11.65 \\
\hline 30 & 56.29 & 1.6 & 11.03 & $\begin{array}{c}\mathrm{l}=20.46 \\
\mathrm{a}=5.87 \\
b=5.03\end{array}$ & 13.04 \\
\hline 45 & 51.25 & 1.99 & 10.680 & $\begin{array}{c}\mathrm{l}=20.74 \\
\mathrm{a}=5.0 \\
\mathrm{~b}=4.94\end{array}$ & 13.59 \\
\hline
\end{tabular}

It was observed that moisture content of oyster mushroom ketchup decreased with storage time in PET bottles. Acidity increased with time, which might be due to break down of sugars to acids, during storage. Ascorbic acid content decreased with storage period. L value increased with storage time indicating the colour became lighter, which might be due to degradation of colour pigments. There was not much change in ' $a$ ' and ' $b$ ' value during storage. Reducing sugar content increased slightly with storage period, which might be due to inversion of sugars.

Glass bottle storage gave better retention of all the quality parameters in comparison to PET bottle storage.

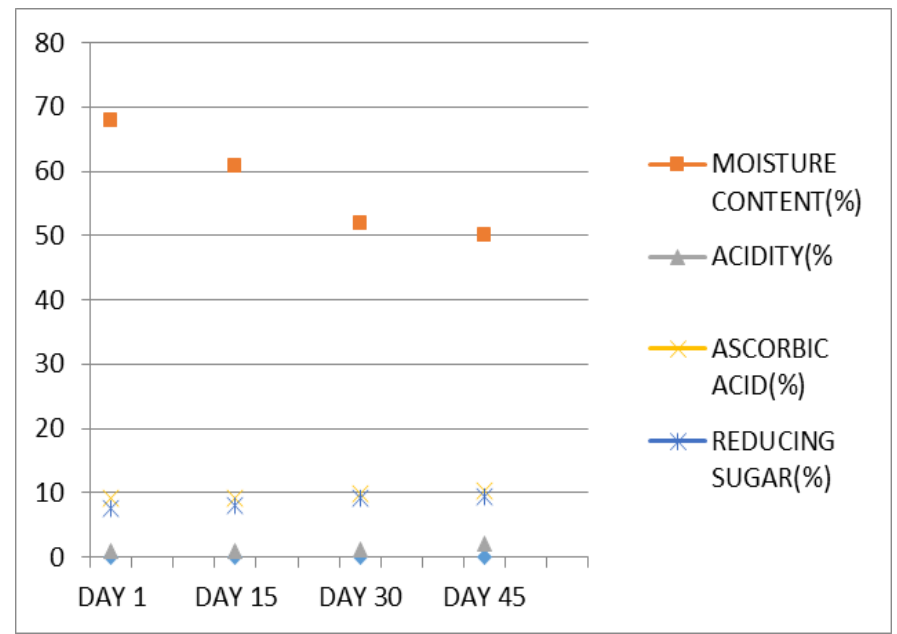

Table 5: Changes in moisture content of mushroom soup powder with storage time

\begin{tabular}{|c|c|c|c|c|}
\hline Packaging material & 0 day & 15 day & 30 day & 45 day \\
\hline LDPE & $7.837 \%$ & $7.463(\%)$ & $6.538(\%)$ & $5.932(\%)$ \\
\hline HDPE & $7.837 \%$ & $7.082(\%)$ & $6.285(\%)$ & $6.074(\%)$ \\
\hline PP & $7.837 \%$ & $7.73(\%)$ & $6.79(\%)$ & $6.034(\%)$ \\
\hline Laminated Aluminium foil & $7.837 \%$ & $7.563(\%)$ & $7.39(\%)$ & $7.32(\%)$ \\
\hline
\end{tabular}

From Table 5 it was observed that moisture content of oyster mushroom soup powder decreased with storage time in the packaging materials. After 45 days of storage laminated aluminium foil pouch showed the best result in terms of moisture retention.

Fig 7: Graphical representation of change in various parameters of oyster mushroom ketchup and soup powder respectively with time 


\section{Summary and Conclusion}

From storage study it was concluded that glass bottle storage is preferred for oyster mushroom ketchup and laminated aluminium pouch was considered best for oyster mushroom soup powder.

\section{References}

1. Adsule PG, Girija V, Amba Dan, Tewari RP. A note of simple preservation of oyster mushroom (Pleurotus sajor caju). Indian Journal of Mushrooms. 1981; 7(1, 2):2-5.

2. Ahlawat OP, Rai RD, Ahlawat K, Verma RN. Control of browning in white button mushroom (Agaricus bisporus) Indian Food Packer. 2000a; 54(1):60-64.

3. Ahlawat OP, Rai RD, Ahlawat K, Verma RN. Preserving quality of button mushroom. Bussiness Star. 2000b; 11(6): 23-24.

4. Anonymous. Retrieved on Mar 2017 from, https://www.kisansuvidha.com/postharves, 2017 a.

5. Anonymous Retrieved on Mar 2017 from, http:// nhb.gov.in/report files/oyster, 2017 b.

6. Arumuganathan T, Rai RD, Hemakar AK. Preparation of pickle from oyster mushroom (Pleurotus florida). Processed food Industry. 2003; 7(3):21-23.

7. Cook RJ, Papendick RI. Role of water potential in microbial growth and development of plant disease, with special reference to post-harvest pathology. Hort Sci. 1978; 13(5):559-564.

8. Czapski J. Mushrooms quality as affected by washing and storage conditions. Vegetable crops research bulletin. 2002; 56:121-128.

9. Das N, Pattanayak SC. Effect of blanching on quality of frozen mushrooms. Mushroom Research. 2003; 12(2):125-126.

10. Rai RD, Arumuganathan T. Post Harvest Technology of Mushrooms, Technical Bulletin-2008, NRCM, ICAR, Chambaghat, Solan-1731213, (H.P.), 2008. 